\title{
INSIDEN CARPAL TUNNEL SYNDROME BERDASARKAN ANAMNESIS PADA KARYAWAN BANKDI KOTA BITUNG SULAWESI UTARA
}

\author{
${ }^{1}$ Denniel Saerang \\ ${ }^{2}$ Mieke Kembuan \\ ${ }^{2}$ Winifred Karema
}

\author{
${ }^{1}$ Kandidat Skripsi Fakultas Kedokteran Universitas Sam Ratulangi Manado \\ ${ }^{2}$ Bagian /SMF Neurologi Fakultas Kedokteran Universitas Sam Ratulangi Manado \\ Email: dr.saerang@icloud.com
}

\begin{abstract}
Abstrak: Carpal Tunnel Syndrome (CTS) is pressure neuropathy against nervous medianus in carpal tunnel on the wrists, exactly on the bottom of the fleksor retinaculum. CTS can occur due to excessive body activities or due to repeated movements including the use of computers. This could result in life problems, such as reduction in productivity of work and also the rising cost of health care. In Indonesia, CTS generally is not specified independently but it is incorporated into the accident of working muscle and bones groups. This study aimed to know the incidence of CTS among employees in Bitung. The was a descriptive study with a cross sectional design. Samples were 47 people who worked in banks: BNI and BCA in Bitung. Data were obtained by using questionnaire. The results showed that the incidence of CTS was found in $28 \%$ of bank employees; $13 \%$ had right unilateral CTS, $2 \%$ had left unilateral CTS, and $13 \%$ had bilateral CTS.
\end{abstract}

Keywords: Carpal Tunnel Syndrome, computer, employees of banks

\begin{abstract}
Abstrak: Carpal Tunnel Syndrome (CTS) merupakan neuropati tekanan terhadap nervus medianus dalam terowongan karpal pada pergelangan tangan, tepatnya di bawah fleksor retinakulum. CTS dapat terjadi karena aktifitas tubuh yang berlebihan atau karena pergerakan yang berulang termasuk penggunaan komputer. Hal ini dapat mengakibatkan suatu masalah khusus dalam kehidupan, seperti penurunan produktivitas pekerjaan serta meningkatnya biaya untuk kesehatan. Di Indonesia umumnya CTS tidak dispesifikasi sendiri melainkan dimasukkan dalam kecelakaan kerja kelompok otot dan tulang. Penelitian ini bertujuan untuk mengetahui insiden CTS pada karyawan di Kota Bitung. Metode penelitian deskriptif dengan menggunakan rancangan potong lintang. Sampel berjumlah 47 orang yang bekerja di Bank BNI dan BCA di Kota Bitung. Data diperoleh menggunakan kuisioner. Hasil penelitian menunjukkan bahwa insiden CTS ditemukan pada 28\% karyawan Bank di kota Bitung: 13\% mengalami CTS unilateral kanan, 2\% mengalami CTS unilateral kiri, dan 13\% mengalami CTS bilateral.
\end{abstract}

Kata kunci: Carpal Tunnel Syndrome, komputer, pekerja Bank BNI \& Bank BCA

Carpal Tunnel Syndrome merupakan tekanan neuropati terhadap nervous medianus dalam trowongan karpal pada pergelangan tangan, tepatnya di bawah fleksor retinakulum. CTS merupakan kondisi dimana nervous medianus terjadi penekanan di bagian trowongan karpal dan menggangu fungsional umum. ${ }^{1-4}$ Carpal Tunnel Syndrome umumnya menghasilkan rasa sakit, kesemutan, terbakar, mati rasa,atau beberapa kombinasi dari gejala ini pada aspek palmar ibu jari, jari telunjuk, jari tengah, dan setengah radial dari jari manis. ${ }^{5,9}$ Gerakan tangan ${ }^{5}$ mengetuk, 
fleksi, dan ekstensi yang berulang-ulang, serta mengetik ${ }^{8}$ menyebabkan kompresi saraf median diterowongan karpal merupakan hasil dari ketidaksesuaian antara volume isi kanal dan ukuran relatif. ${ }^{3}$

Selama tahun 2003 sampai 2005 terjadi peningkatan kasus CTS pada karyawan akibat gerakan repetitif pada penggunaan komputer dalam frekuensi yang sering dan durasi yang lama dari 76 kasus menjadi 112 kasus. Hal ini mengakibatkan terjadinya peningkatan angka absensi kerja, produktivitas karyawan dan gangguan kesehatan yang teakumulasi. Apalagi dengan adanya perkembangan teknologi yang sangat maju menuntut para perkerja sering menggunakan komputer untuk membantu memundahkan pekerjaan.

Penelitian Lie T Merjanti (2004) mendapatkan prevalensi sebesar $27 \%$ pada wanita di pengolahan makanan. ${ }^{2}$ Di Indonesia umumnya CTS tidak dispesifikasi sendiri melainkan dimasukkan ke dalam kecelakaan kerja kelompok otot dan tulang.

Mendiagnosis CTS harus berdasarkan kombinasi dari tanda klinis yang di temukan, yaitu: rasa nyeri, baal, atau seperti terkena sengatan listrik yang dipersarafi oleh n. medianus, rasa kebas, dan terjadi di jari pertama sampai setengah jari ke tiga. ${ }^{8}$ Beberapa pemeriksaan fisik yang dapat dilakukan untuk mendiagnosis CTS yaitu antara lain: tes Phalen dan tes Tinel, serta dapat dilakukan tes neurologi lainnya seperti EMG.

\section{METODE PENELITIAN}

Jenis penelitian yang dilakukan ialah deskriptif dengan desain potong lintang. Penelitian dilakukan pada bulan November - Desember 2013 di Bank BNI dan BCA di kota Bitung, Sulawesi Utara. Sampel penelitian harus memenuhi kriteria inklusi yaitu seluruh karyawan bank BNI dan BCA yang telah bekerja minimal 1 tahun dan bersedia mengikuti penelitian melalui pengisian informed consent. Variabel penelitian meliputi variabel tergantung yaitu Carpal Tunnel Syndrome dan variabel bebas yaitu Umur, Jenis Kelamin, Tingkat
Pendidikan, Masa Kerja, dan Jenis Pekerjaaan.

Pengambilan data diperoleh dengan menggunakan kuisioner serta tanya jawab langsung dengan responden kemudian hasil penelitian diolah di komputer.

\section{HASIL PENELITIAN}

Jumlah karyawan bank BCA dan bank BNI yang menjadi responden pada penelitian ini ialah 50 orang yang bekerja selama kurang lebih 6-8 jam sehari. Yang memenuhi kriteria inklusi berjumlah 47 orang. Mayoritas respoden ialah perempuan berjumlah 31 orang (66\%) sedangkan lakilaki berjumlah 16 orang (35\%), yang terdiri dari usia 20-25 tahun 13 orang (28\%) dan 25-50 tahun 34 orang (72\%). Kebanyakan responden memiliki tingkat pendidikan strata 1 yaitu $81 \%$ (38 orang), sebagian besar telah melakukan masa kerja 1-5 tahun 51\% (24 orang), dan 30\% responden (14 orang) merupakan karyawan di bagian teller (Tabel 1).

Tabel 1. Karakteristik responden berdasarkan tingkat pendidikan, masa kerja, jenis pekerjaan

\begin{tabular}{lcc}
\hline Variabel & Jumlah (n) & \% \\
\hline Tingkat & & \\
Pendidikan & & \\
SMA & 2 & 4 \\
Diploma & 6 & 13 \\
Strata 1 & 38 & 81 \\
Strata 2 & 1 & 2 \\
Strata 3 & 0 & 0 \\
Masa Kerja & & \\
1-5 tahun & 24 & 51 \\
5-10 tahun & 10 & 21 \\
>10 tahun & 13 & 28 \\
Jenis Pekerjaan & & \\
Teller & 14 & 30 \\
Customer service & 12 & 26 \\
Marketing & 9 & 19 \\
Administrasi & 12 & 26 \\
\hline
\end{tabular}

\section{Insiden Carpal Tunnel Syndrome}

Pada penelitian ini diagnosis CTS ditentukan bila responden merasakan tanda khas CTS yaitu merasa nyeri, baal, atau kesemutan pada jari ibu, jari telunjuk, jari tengah dan setengah jari manis ditangan kiri atau tangan kanan (unilateral) atau pada kedua tangan (bilateral). Prevalensi 
CTS pada penelitian ini ialah 28\% atau 13 orang dari 47 responden. Dari 13 orang yang menderita CTS ditemukan 6 orang (13\%) mengalami CTS unilateral kanan, 1 orang (2\%) mengalami CTS unilateral kiri dan 6 orang (13\%) mengalami CTS bilateral atau kedua tangan (Tabel 2).

Tabel 2. Distribusi Insiden CTS berdasarkan lokasi

\begin{tabular}{lcc} 
Variabel & n & \% \\
CTS Unilateral kanan & 6 & 13 \\
CTS Unilateral kiri & 1 & 2 \\
CTS Bilateral (kedua tangan) & 6 & 13 \\
\hline
\end{tabular}

Dari Tabel 3 dapat di lihat kebanyakan responden mengeluhkan nyeri 7 orang dari 13 penderita CTS (54\%) kemudian diikuti dengan keluhan rasa kebas dan kesemutan sebesar 6 orang dari 13 penderita CTS (46\%).

Tabel 3. Distribusi Insiden CTS berdasarkan keluhan

\begin{tabular}{lcc} 
Keluhan & n & \% \\
\hline Nyeri & 7 & 54 \\
Rasa baal dan kesemutan & 6 & 46 \\
Nyeri dan rasa baal dan kesemutan & 0 & 0 \\
\hline
\end{tabular}

\section{CTS Berdasarkan Faktor Risiko}

Pada Tabel 4 dapat dilihat dari 47 responden ternyata CTS lebih banyak diderita oleh perempuan yaitu $24 \%$ (11 orang) sedangkan laki-laki sebesar 4\% (2 orang). Berdasarkan usia, 26-30 tahun merupakan usia yang terbanyak menderita CTS yaitu 11\% (5 orang), kemudian usia 20-25 tahun 9\% (4 orang) dan usia 31-35 tahun, usia 36-40 tahun, serta usia 41-45 tahun dan 46-50 tahun didapatkan masingmasing $2 \%$ (1 orang).

Tingkat pendidikan menunjukkan bahwa strata 1 memiliki persentase tertinggi yaitu $23 \%$ atau 11 orang dan diploma sebesar $4 \%$ atau 2 orang. Dari jenis pekerjaan, prevalensi CTS terbesar adalah teller sebesar $46 \%$ (6 orang), selanjutnya bagian administrasi 31\%(4 orang) dan yang terakhir customer service 23\% (3 orang).
Dilihat dari masa kerja, ternyata masa kerja 1-5 tahun prevalensinya lebih tinggi yaitu 17\% (8 orang). Salah satu faktor yang di teliti yaitu posisi tangan saat waktu kerja menunjukan posisi tangan yang lebih tinggi dari keyboard komputer saat kerja sebesar 21\% (10 orang), sedangkan yang saat bekerja posisi tangan lebih rendah dari keyboard komputer saat kerja 6\% (3 orang).

Tabel 4. Distribusi insiden CTS berdasarkan faktor risiko

\begin{tabular}{ccc}
\hline Pertanyaan & n & $\mathbf{\%}$ \\
\hline Jenis Kelamin & & \\
Laki-laki & 2 & 4 \\
Perempuan & 11 & 23
\end{tabular}

Umur

$\begin{array}{lcc}\text { 20-25 tahun } & 4 & 9 \\ \text { 26-30 tahun } & 5 & 11 \\ 31-35 \text { tahun } & 1 & 2 \\ 36-40 \text { tahun } & 1 & 2 \\ 41-45 \text { tahun } & 1 & 2 \\ 46-50 \text { tahun } & 1 & 2\end{array}$

Tingkat Pendidikan

$\begin{array}{lcc}\text { SMA } & 0 & 0 \\ \text { Diploma } & 2 & 4 \\ \text { strata } 1 & 11 & 23 \\ \text { strata 2 } & 0 & 0 \\ \text { stara 3 } & 0 & 0\end{array}$

Jenis Pekerjaan

Teller

Customer Service

$3-6$

Administrasi $\quad 4 \quad 9$

Marketing $\quad 0 \quad 0$

Masa Kerja

$\begin{array}{lcc}1-5 \text { tahun } & 8 & 17 \\ 6-10 \text { tahun } & 3 & 6 \\ >10 \text { tahun } & 3 & 6\end{array}$

Posisi Tangan

Posisi tangan lebih tinggi

daripada keyboard $\quad 10 \quad 21$

Posisi tangan lebih rendah

daripada keyboard

36

\section{Pengetahuan Responden Tentang Carpal Tunnel Syndrome}

Pada penelitian ini disertakan beberapa pertanyaan umum mengenai CTS kepada responden untuk menilai pengetahuan mereka mengenai CTS. 
Tabel 5. Pengetahuan Responden terhadap CTS

\begin{tabular}{|c|c|c|}
\hline Pertanyaan & $\mathbf{n}$ & $\%$ \\
\hline \multicolumn{3}{|l|}{$\begin{array}{l}\text { Apakah anda pernah } \\
\text { mendengar tentang CTS }\end{array}$} \\
\hline Ya & 1 & 2 \\
\hline Tidak & 46 & 98 \\
\hline \multicolumn{3}{|l|}{$\begin{array}{l}\text { Bila ya, anda memperoleh } \\
\text { informasi dari mana }\end{array}$} \\
\hline Internet & 1 & 2 \\
\hline Buku & 0 & 0 \\
\hline Tetangga & 0 & 0 \\
\hline Koran & 0 & 0 \\
\hline Dokter & 0 & 0 \\
\hline Tidak tahu & 46 & 98 \\
\hline \multicolumn{3}{|l|}{$\begin{array}{l}\text { Menurut anda, CTS dapat } \\
\text { menyerang pada organ }\end{array}$} \\
\hline Kepala & & 0 \\
\hline Kaki & & 0 \\
\hline Tangan & 7 & 15 \\
\hline Tidak tahu & 40 & 85 \\
\hline \multicolumn{3}{|l|}{$\begin{array}{l}\text { Menurut anda, apakah } \\
\text { faktor penyebab CTS }\end{array}$} \\
\hline Tidur & 1 & 2 \\
\hline Merokok & 1 & 2 \\
\hline Gerakan berulang & 1 & 2 \\
\hline Tidak tahu & 44 & 94 \\
\hline \multicolumn{3}{|l|}{$\begin{array}{l}\text { Menurut anda, tempat } \\
\text { melakukan konsultasi jika } \\
\text { anda menderita CTS }\end{array}$} \\
\hline Dukun & 0 & 0 \\
\hline Tukang pijat & 1 & 2 \\
\hline Dokter spesialis saraf & 18 & 38 \\
\hline Tidak tahu & 28 & 60 \\
\hline
\end{tabular}

Tabel 5 ini membuktikan dari 20 responden hanya ada satu orang (2\%) yang mengetahui atau pernah mendengar tentang CTS dari internet. Bahkan hanya 15\% (7 orang) yang mengetahui bahwa CTS dapat menyerang organ tangan 85\% tidak tahu soal itu (40 orang). Begitupun dengan pertanyaan mengenai faktor penyebab, hanya 1orang atau 2\% yang tahu CTS disebabkan gerakan yang berulang dan 94\% (44 orang) mengatakan tidak tahu soal itu, namun 5\% (1 orang) mengatakan karena tidur, 5\% (1 orang) mengatakan karena merokok. Pertanyaan mengenai tempat konsultasi 38\% (18 orang) tahu jika nanti ia terkena CTS akan berkonsultasi di dokter specialis saraf. Namun 60\% (28 orang) tidak tahu soal itu, dan $2 \%$ (1 orang) memilih untuk pergi ke tukang pijat.

\section{BAHASAN}

Dalam penelitian ini, dari 47 orang ditemukan 13 orang mengalami gejala khas CTS yaitu CTS unilateral kanan 6 orang (13\%), CTS unilateral kiri 1 orang (2\%) dan CTS bilateral atau kedua-dua tangan 6 orang (13\%), sehingga didapatkan insiden CTS pada karyawan Bank di kota Bitung sebesar 28\% (13/47 orang). Hal ini sesuai dengan penelitian yang di lakukan oleh Lie T. Merjanti (2004) yang mengatakan prevalensi CTS sebesar 27\%. Juga penelitian yang dilakukan oleh Tana Lusianawati (2002) dimana dari 814 pekerja garmen di temukan sebesar 165 orang (20,3\%). Namun tidak sesuai dengan penelitian yang dilakukan oleh The National Institute of Occupation safety and Health pada tahun 1997 yaitu 50\% pekerja di negara maju menderita CTS diakibatkan karena aktifitas di tempat kerja.

Berdasarkan keluhan yang dirasakan oleh karyawan maka nyeri merupakan keluhan yang paling banyak dialami yaitu 7 dari 13 orang yang menderita CTS (54\%). Keluhan rasa baal dan kesemutan ditemukan pada 6 dari 13 orang yang enderita CTS (46\%). Hal iIni sesuai dengan penelitian Lie Merjanti dimana kesemutan merupakan keluhan yang terbanyak. Barnhart (1991) mendapati keluhan yang terbanyak muncul pada responden dengan gerakan repetitif ialah nyeri pada satu atau kedua tangan. Hal ini juga mendukung teori yang dikemukakan oleh Bambang Darwono dimana nyeri pada tangan terutama pada pergelangan tangan merupakan gejala yang timbul pada CTS.

Pada penelitian ini juga di temukan bahwa berdasarkan jenis kelamin CTS lebih banyak diderita oleh perempuan yaitu 23\% (11 orang) dan laki-laki 4\% (2 orang) dari 47 responden. Walaupun memang lebih banyak perempuan yang menjadi responden namun penelitian ini juga membuktikan teori yang telah ada dimana CTS lebih sering terjadi pada wanita dibandingkan pria (3:1). Hal ini dikarenakan wanita memiliki terowongan karpal yang lebih kecil dibandingkan pria. Pada beberapa penelitian wanita dikatakan 
lebih banyak menderita CTS karena pengaruh hormon, namun dalam penelitian ini pengaruh hormon tidak diteliti.

Beberapa teori mengemukakan bahwa usia umum terjadinya CTS ialah 30-60 tahun dikarenakan pada orang tua ukuran penampang terowongan 2,5cm dan panjangnya kurang lebih 9-16 meter, namun dalam penelitian ini ditemukan juga CTS pada usia 26-30 tahun yaitu 11\% (5/47 orang), usia 20-25 tahun sebesar 9\% (5/47 orang), diikuti usia 31-50 tahun sebesar 2\%

Bedasarkan tingkat pendidikan ternyata dari 47 responden kebanyakan memiliki pendidikan strata 1 sebesar $23 \%$ (11/47 orang).

Berdasarkan jenis pekerjaan, pekerjaan teller memiliki persentase yang cukup tinggi yaitu 13\% (6/47 orang). Hal ini dikarenakan teller merupakan pekerjaan dengan menggunakan kontraksi otot yang kuat dan disertai dengan gerakan repetitif tinggi yaitu prevalensi $5,6 \%$ menurut ilverstein (1987), ${ }^{3}$ kemudian bagian administrasi 9\% (4/47 orang) dan customer service $6 \%$ (3/47 orang). Hal ini sesuai dengan pustaka yang mengatakan persentase CTS lebih meningkat pada pekerjaan yang sering menggunakan komputer seperti bagian teller, customer service, dan administrasi. OSHA (1999) mencatat bahwa sebanyak 46\% dan 36\% pengolah data dipastikan mengalami CTS. ${ }^{6}$ Mengetik termasuk sebagai salah satu faktor yang menyebabkan kompresi saraf median (Szabo,1989). ${ }^{3}$

Pada penelitian ini ditemukan masa kerja 1-5 tahun merupakan persentase CTS terbesar yaitu 17\% (8/47 orang). Padahal di perkirakan bahwa masa kerja yang lebih lama lebih berisiko terkena CTS karena aktifitas yang dilakukan, Hal ini disebabkan kebanyakan karyawan baru di tugaskan di bagian teller yaitu bagian dengan prevalensi tertingi untuk CTS. Masa kerja yang dapat menyebabkan CTS walaupun persentasenya kecil yaitu masa kerja 6-10 tahun 6\% (3/47 orang) dan masakerja $>10$ tahun $6 \%$ (3/47 orang).

Posisi tangan merupakan salah satu faktor terbesar yang dapat mengakibatkan
CTS. Dari pengamatan kebanyakan karyawan lebih suka meletakan keyboard komputer lebih tinggi dari posisi pergelangan tangan sehingga pergelangan tangan dalam posisi tergantung saat mengetik. Ada juga yang meletakan keyboard komputer lebih rendah dari pada posisi pergelangan tangan sehingga pergelangan tangan menjadi tertekan. Kedua posisi ini dapat menyebabkan tekanan pada nervus medianus dalam terowongan karpal sehingga mengakibatkan terjadinya CTS. Dari posisi tangan ini ditemukan bahwa posisi tangan yang lebih tinggi dari keyboard komputer mengakibatkan 21\% (10/47 orang) menderita CTS dan 6\% (3/47orang) ditemukan pada posisi tangan yang lebih rendah dari keyboard komputer.

\section{Pengetahuan Mengenai Carpal Tunnel Syndrome}

Selain menilai insiden CTS, pada penelitian ini dilakukan juga seleksi untuk mengetahui pengetahuan responden terhadap CTS. Dari 20 responden, hanya ada 1 orang (2\%) yang pernah mendengar atau mengetahui mengenai CTS, yaitu dari internet. Ini mungkin dikarenakan di Indonesia CTS tidak dispesifikasi sendiri melainkan digabungkan bersama dengan kecelakan kerja kelompok otot dan tulang, sehingga tidak diketahui oleh responden. Terlebih lagi tidak ada pelatihan mengenai keselamatan kerja dan bahayanya, namun $15 \%$ (7/47 orang) responden mengetahui CTS menyerang organ tangan.

Mengenai faktor risiko, hanya 2\% atau 1 orang dari 47 responden yang tahu CTS dapat menyerang organ tangan, sedangkan 94\% (44/47 orang) responden tidak tahu,walaupun $2 \%$ (1/47 orang) menjawab karena merokok dan 2\% (1/47 orang) menjawab karena tidur.

Sama halnya ketika ditanyakan soal tempat konsultasi jika responden menderita CTS dari 47 responden 38\% atau 18 orang menjawab benar yaitu pergi ke dokter spesialis saraf, namun $2 \%$ atau 1 orang menjawab pergi ke tukang pijat dan 60\% yaitu 28 orang mengatakan tidak tahu. Dari 
pertanyaan yang dibagikan membuktikan bahwa dari 47 orang hanya $2 \%$ yang tahu mengenai CTS shingga perlu diberikan edukasi bahkan seminar mengenai keselamatan kerja serta bahayanya agar dapat mencegah terjadinya penyakit yang mengganggu aktivitas. Data yang ada membuktikan penggunaan komputer yang intens dapat menjadikan suatu permasalahan sendiri jika menimbulkan suatu penyakit yang akhirnya dapat menurunkan produktivitas pekerjaan serta meningkatnya biaya pemeliharaan kesehatan.

\section{SIMPULAN}

Insiden Carpal Tunnel Syndrome (CTS) ditemukan pada karyawan Bank di kota Bitung, baik yang unilateral maupun bilateral. Karyawan perempuan lebih berisiko. Usia 26-30 tahun memiliki prevalensi tertinggi. Tingkat Pendidikan Strata 1 memiliki prevelensi tertinggi menderita CTS. Karyawan bagian teller terbanyak yang ditemukan dengan CTR, diikuti bagian administrasi dan bagian Customer service. Dilihat dari masa kerja, 1-5 tahun memiliki prevalensi tertinggi. Posisi tangan yang lebih tinggi dari keyboard komputer lebih seering menderita CTR daripada posisi tangan yang lebih rendah dari keyboard. Dari 20 karyawan hanya ada 1orang (2\%) yang pernah mendengar dan mengetahui mengenai CTS, walaupun 15\% karyawan mengetahui CTS menyerang organ tubuh bagian tangan dan 38\% responden mengetahui dokter spesialis saraf merupakan tempat konsultasi.

\section{SARAN}

Untuk mecegah dan mengurangi kejadian CTS di tempat kerja, maka di sarankan sebelum bekerja melakukan pemanasan ringan pada tangan, serta memperhatikan faktor-faktor risiko yang dapat menimbulkan atau memperparah CTS.

\section{DAFTAR PUSTAKA}

1. Tana L. Sindroma Trowongan Karpal pada Pekerja, Pencegahan dan Pengobatan. Jakarta: Depertemen Kesehatan Republik Indonesia, 2003;22 :99-104

2. Sitorus R. Sindrom Trowongan Karpal. Jakarta: Universitas Indonesia, 2005.

3. Kostopoulos D. Treatment of Carpal Tunnel Syndrome: a Review of The Non Surgerycal Approachs with Emphasis in Neural Mobilization: Journal of Body work and Movement Therapy. 2004;8:2-8.

4. Baharudin M. Carpal Tunnel Syndrome. Jakarta: Universitas Indonesia, 2005.

5. Rosati P. Carpal Tunnel Syndrome; It's Work: Option Incoporate Ontario, 2009.

6. Febriyanti D. Kajian Resiko Komulative. Jakarta: Universitas Indonesia, 2008.

7. Sesto M, Radun R, Salvi F. Functional Deficits in Carpal Tunnel Syndrome: America Journal of Industrial Medicine. 2003;44:133-40.

8. Rambe A. Sindrome Terowongan Karpal. Medan: Bagian Neurologi RSUP H. Adam Malik, 2004.

9. Ibrahim I, Khan WS, Goddard N, Smithan P. Carpal Tunnel Syndrome: A Review of The Recent Literature. The Open Orthopedic Journal. 2012:69-76.

10. Simons B, Katz J. Carpal Tunnel Syndrome. N Engl J Medicine. 2002; 23:1807-12.

11. Gibbs J, Horton-szar D. Neurology (2nd ed). Turnner, Bahra, Cikurel. Crash Course, 2006; p. 139-40.

12. Gorsche R. Carpal Tunnel Syndrome: The Canadian Journal of CME, 2001.

13. Ross S. Carpal Tunnel Syndrome: Diagnosis and Treatment Guideline. Departement of Consumer and Business Center, 2005; p. 2-13. 